\title{
Secretin Human
}

National Cancer Institute

\section{Source}

National Cancer Institute. Secretin Human. NCI Thesaurus. Code C47713.

A synthetic human therapeutic agent which is chemically identical or similar to endogenous secretin, a peptide hormone found in the mucosal S-cells of the proximal small intestine. Secretin stimulates the pancreatic acinar cells and ductal epithelial cells to emit bicarbonate rich digestive fluids, thereby increases duodenal bicarbonate level. Bicarbonate neutralizes acidity of the intestines, consequently increasing the $\mathrm{pH}$ and facilitating the action of intestinal digestive enzymes. In addition, secretin stimulates the stomach and the liver to produce pepsin and bile, respectively. Both pepsin and bile aide the digestive action of the duodenum, which resulting in the prevention of gastric inflammation. 